CLINICAL STUDY

\title{
Influence of hormonal control on LH pulsatility and secretion in women with classical congenital adrenal hyperplasia
}

\author{
Anne Bachelot, Zeina Chakhtoura, Geneviève Plu-Bureau ${ }^{1}$, Mathieu Coudert ${ }^{2}$, Christiane Coussieu ${ }^{3}$, \\ Yasmina Badachi $^{4}$, Jérome Dulon, Beny Charbit ${ }^{5}$ and Philippe Touraine on behalf of the CAHLH study group ${ }^{\dagger}$ \\ AP-HP, Department of Endocrinology and Reproductive Medicine, Centre de Référence des Maladies Endocriniennes Rares de la Croissance, Pitié-Salpêtrière \\ Hospital (Groupe Hospitalier Pitié-Salpêtrière), Université Pierre et Marie Curie, Site Pitié, 47-83 Boulevard de l'Hôpital, 75013 Paris, France, ${ }^{1}$ AP-HP, \\ Department of Gynecological Endocrinology, Cochin Hospital, Université Paris Descartes, Paris, France, ${ }^{2}$ AP-HP, Clinical Research Unit, ${ }^{3}$ AP-HP, \\ Department of Hormonal Biochemistry, ${ }^{4}$ AP-HP, Department of Radiology and ${ }^{5}$ AP-HP, Centre d'investigation clinique, Pitié-Salpêtrière Hospital, \\ Paris, France \\ (Correspondence should be addressed to P Touraine; Email: philippe.touraine@psl.aphp.fr) \\ ${ }^{\dagger}$ (CAHLH study group details have been given in the acknowledgement section)
}

\begin{abstract}
Objective: Women with classical congenital adrenal hyperplasia (CAH) exhibit reduced fertility due to several factors including anovulation. This has been attributed to a disturbed gonadotropic axis as in polycystic ovary syndrome (PCOS), but there is no precise evaluation. Our aim was to evaluate the gonadotropic axis and LH pulsatility patterns and to determine factor(s) that could account for the potential abnormality of LH pulsatility.

Design: Case/control study.

Methods: Sixteen CAH women (11 with the salt-wasting form and five with the simple virilizing form), aged from 18 to 40 years, and 16 age-matched women, with regular menstrual cycles ( $28 \pm 3$ days), were included. LH pulse patterns over $6 \mathrm{~h}$ were determined in patients and controls.

Results: No differences were observed between patients and controls in terms of mean LH levels, $\mathrm{LH}$ pulse amplitude, or LH frequency. In CAH patients, LH pulsatility patterns were heterogeneous, leading us to perform a clustering analysis of LH data, resulting in a two-cluster partition. Patients in cluster 1 had similar LH pulsatility patterns to the controls. Patients in cluster 2 had: lower LH pulse amplitude and frequency and presented menstrual cycle disturbances more frequently; higher 17-OH progesterone, testosterone, progesterone, and androstenedione levels; and lower FSH levels.

Conclusions: LH pulsatility may be normal in CAH women well controlled by hormonal treatment. Undertreatment is responsible for hypogonadotropic hypogonadism, with low LH pulse levels and frequency, but not PCOS. Suppression of progesterone and androgen concentrations during the follicular phase of the menstrual cycle should be a major objective in these patients.
\end{abstract}

European Journal of Endocrinology 167 499-505

\section{Introduction}

Congenital adrenal hyperplasia $(\mathrm{CAH})$ describes a group of inherited autosomal recessive disorders, with 21-hydroxylase deficiency (210HD) being the most common form and accounting for about $95 \%$ of all cases (1). Classical 210HD CAH is characterized by severe mutations in the CYP21A2 gene, leading to cortisol deficiency, testosterone and progesterone overproduction, and virilization of the female external genitalia due to prenatal androgen excess. Classical $\mathrm{CAH}$ is further classified into the salt-wasting (SW) or simple virilizing (SV) forms, reflecting the degree of aldosterone deficiency (1).

Reduced fertility has been reported in patients with classical CAH, especially in SW women. This has been attributed to several factors including psychological factors such as different gender behavior and low maternal interests; post-surgical difficulties with intercourse, anovulation, and menstrual irregularities; and the effect of progesterone hypersecretion on endometrial receptivity (2). The precise mechanisms underlying menstrual irregularities and anovulation remain uncertain, involving overproduction of androgen and/or progesterone $(3,4)$. One study of LH pulsatility was conducted in women with the nonclassical (NC) form, who were compared with controls and women with polycystic ovary syndrome (PCOS) (5). This study showed that PCOS and NC CAH women had increased LH pulse amplitude compared with control women, but only PCOS women had decreased LH interpulse interval compared with controls. Data suggesting abnormalities of LH pulsatility in PCOS women are related to a relative insensitivity to progesterone-induced $\mathrm{LH}$ inhibition 
$(6,7,8,9)$, an abnormality that can be reversed by blockade of androgen action (10). Gonadotropin abnormalities of $\mathrm{NC} \mathrm{CAH}$ women therefore appear to be intermediate between those of controls and PCOS patients (5). However, these results are not extrapolable to women with a classical form of $\mathrm{CAH}$, as they are exposed to androgens and progesterone oversecretion since the prenatal period.

Indeed, the disturbing factor for the gonadotropic axis in women with classical CAH may also be explained by early exposure to androgens and progesterone oversecretion since the prenatal period. Some authors have therefore suggested that high levels of fetal or perinatal androgens favor LH hypersecretion at puberty, leading to anovulation and polycystic ovaries $(11,12)$. However, the conclusions of these studies are almost all speculative, as there are no studies on LH pulsatility in these women.

In such impact, the aim of our study was thus to evaluate LH pulsatility patterns in women with classical CAH compared with normal cycling women and to determine factors that might account for the potential abnormality of LH pulsatility.

\section{Materials and methods}

\section{Patients and controls}

Classical $\mathrm{CAH}$ women were included in the study if they fulfilled the following criteria: aged between 18 and 40 years, previous molecular analysis of the CYP21A2 gene confirming the presence of a classical form of $\mathrm{CAH}$, FSH level <15 IU/l, Hb > $12.5 \mathrm{~g} / \mathrm{dl}$, and absence of combined hormonal treatment during the past 3 months. They were divided into the classical SW form and the classical SV form according to the clinical data and the predicted severity of the mutations as previously described (13).

Age-matched women with regular menstrual cycles were recruited by the Clinical Investigation Centre and included as controls. Additional criteria for inclusion were FSH level $<15 \mathrm{IU} / \mathrm{l}, \mathrm{Hb}>12.5 \mathrm{~g} / \mathrm{dl}$, and absence of combined hormonal treatment during the previous 3 months.

The study was designed to detect a difference in $\mathrm{LH}$ pulse period and amplitude between $\mathrm{CAH}$ patients and controls (5). We chose to set the expected pulse period at 99 (10) $\mathrm{min}$ for patients and 111 (8.6) $\mathrm{min}$ for controls, and the expected amplitude was $4.55(0.4)$ $\mathrm{IU} / \mathrm{ml}$ for patients and $6.95(0.4) \mathrm{IU} / \mathrm{ml}$ for controls (14). Comparison was based on a Mann-Whitney $U$ test at a 0.025 significance level (Bonferroni correction for two criteria). Using these hypotheses, 16 patients and 16 controls were necessary to achieve power of at least $80 \%$ for each comparison.

Eighteen $\mathrm{CAH}$ patients were included in our study. One was lost to follow-up and did not participate in the
LH pulse study. One was excluded due to the presence of an ovarian cyst secreting estradiol $\left(\mathrm{E}_{2}\right)$ on the day of the study. Seventeen age-matched women were included as controls; one was excluded due to the presence of high 17-OH progesterone (17-OHP) levels suggesting the presence of a $\mathrm{NC}$ form of $210 \mathrm{HD}$. The study analysis was thus based on 16 patients and 16 controls.

\section{Study protocol}

This study was a single-center transversal study conducted among patients at the Department of Endocrinology and Reproductive Medicine (Paris, France). Ethical approval was granted by the Ethics Committee of the Pitié-Salpêtrière Hospital (Paris, France; registration number: P070502). Written informed consent was obtained from all subjects. This study was performed in accordance with the Declaration of Helsinki. From 2008 to 2010, CAH patients and age-matched control women were studied at the Clinical Investigation Centre. The study was conducted during the early follicular phase for control women and $\mathrm{CAH}$ patients with regular menstrual cycles. For patients with oligomenorrhea and amenorrhea, progestin (dydrogesterone, $20 \mathrm{mg} /$ day) was administrated over 10 days, and the study was conducted on day 3-6 after progestin-induced menstrual bleeding or on day 10 after progestin withdrawal in the absence of menstrual bleeding. Urinary hCG was assessed in all subjects to exclude pregnancy. The following clinical characteristics were recorded in all subjects: age, genotype, age at menarche, history of menstrual cycles, number of previous pregnancies, weight, height, waist and hip circumferences, presence of hirsutism (a score $>8$ in the modified Ferriman-Gallwey scale) (14), and daily dose of hydrocortisone and fludrocortisone for $\mathrm{CAH}$ patients. Baseline hormonal measurements were assessed in all subjects, under their regular treatment for CAH patients. Subjects then underwent determination of LH pulsatility by blood sampling every $10 \mathrm{~min}$ for serum LH over a 6 -h period. These studies were performed between 0800 and $1400 \mathrm{~h}$. Thereafter, the CAH women underwent pelvic sonography to rule out the presence of a dominant follicle or corpus luteum in patients that do not exhibit regular menstrual cycles.

\section{Hormonal assays}

Serum and plasma samples were stored at $-20{ }^{\circ} \mathrm{C}$ until analysis. Baseline samples of all subjects were assayed in a single batch. Serum FSH, $\mathrm{E}_{2}$, progesterone, total testosterone, SHBG, and DHEAS were measured by the Modular E170 automated chemiluminescent immunometric method (Roche Diagnostics) with an intra-assay coefficient of variation (CV) of $<3.3 \%$. Serum 17-OHP was measured by RIA MG12181 (IBL, Hamburg, Germany) with an intra-assay CV of $<6.2 \%$. Serum androstenedione was measured, after extraction, by RIA 
IM0674 (Immunotec, Marseille, France) with an intraassay $\mathrm{CV}$ of $<7.1 \%$. Serum LH was measured in duplicate by automated chemiluminescent immunometric method Modular E170 (Roche Diagnostics). All samples from an individual experiment for each individual were assayed in a single batch. The limit of detection of the assay was $0.1 \mathrm{mIU} / \mathrm{ml}$. The intra-assay and interassay $\mathrm{CV}$ at specific concentrations were specifically measured during the study: the intra-assay CV values were $5.2,2.4,1.3,1.3$, and $0.9 \%$ at $0.3,1.2$, $4.5,8.0$, and $14.7 \mathrm{mIU} / \mathrm{ml}$ respectively, and the interassay $\mathrm{CV}$ were $2.1,1.5,1.6$, and $1.7 \%$ at 1.2 , $4.5,8.0$, and $14.7 \mathrm{mIU} / \mathrm{ml}$ respectively.

\section{LH pulsatility analysis}

Endogenous LH secretion was analyzed according to the algorithm of Thomas et al. A largely model-free computerized peak detection algorithm was used to quantify statistically significant $\mathrm{LH}$ pulses in relation to measurement error (15). A $2 \times 1$ test cluster size was used to test for rises and falls in the data and $t$-statistics of 2.0 for significant increases and falls in LH peaks. Cluster analysis was validated to quantify pulsatile properties of LH (16) in earlier studies.

\section{Statistical analysis}

Statistical analysis was performed using the SAS 9.2 Software package (SAS Institute, Cary, NC, USA). Comparison of $\mathrm{LH}$ pulse amplitude and $\mathrm{LH}$ pulse frequency (main analysis) was two sided at a 0.025 significance level (Bonferroni correction), and other statistical tests were two sided at the $0.05 \alpha$ level. Quantitative data were presented as median and range and were compared between $\mathrm{CAH}$ women and controls using a Mann-Whitney $U$ test. Qualitative data were presented by absolute frequency and were compared using Fisher's exact test.

An explanatory factor analysis of LH data was performed to determine the factors (i.e. hidden underlying variables) that could summarize LH pulsatility data: pulse frequency, pulse amplitude, pulse area, LH mean, pulse amplitude variability, and pulse area variability. The number of factors was first determined using the eigenvalues method (17). The principle of this method is to compute the eigenvalues of the variance matrix and to keep the first greatest ones. Factors were determined using promax rotation and computed as linear combination (scores) of pulsatility variables. A clustering analysis of $\mathrm{LH}$ data was then performed to find out if there were several different profiles of $\mathrm{LH}$ pulsatility among our subjects. We used Ward's hierarchical clustering method to partition subjects into clusters, with individuals in the same cluster having similar results in terms of pulse frequency, pulse amplitude, pulse area, LH mean, pulse amplitude variability, and pulse area variability (18). The principle of hierarchical clustering methods is to iteratively join clusters until only one cluster remains. Ward's method consists of minimizing the ANOVA sum of squares between all candidate partitions at each clustering step. The number of clusters was not defined in advance and this clustering was performed on $\mathrm{CAH}$ patients. Factor analysis and clustering were also performed on all individuals to assess which clusters of patients were associated with the control population. Cluster distribution was then compared between $\mathrm{CAH}$ patients and controls using Fisher's exact test.

\section{Results}

\section{Clinical and hormonal characteristics of CAH women and controls}

The baseline clinical characteristics of patients and control women are shown in Table 1. Age, age at menarche, and BMI did not differ between the two groups. In the CAH group, 11 patients had the SW form and five the SV form. Patients were classified according to predicted mutation severity: group 0 , null mutation $(n=1,6 \%)$; group A, homozygous for IVS2 splice mutation or compound heterozygous for IVS2 and null mutations $(n=8,50 \%)$; and group B, homozygous or compound heterozygous for I172N mutation $(n=7$, $44 \%$ ). No patients had any prior pregnancy. Six had regular menstrual cycles, four presented oligomenorrhea, and six presented amenorrhea. Hirsutism (a score of $>8$ in the modified Ferriman-Gallwey scale) was detected at physical examination in seven patients. The waist-to-hip ratio was higher in patients than in controls, but this difference was not statistically significant $(P=0.06)$.

The baseline hormonal characteristics of patients and controls are shown in Table 2. As expected, 17-OHP levels were higher in patients than in controls $(8.04$ $(0.19-475.00)$ vs $0.83(0.40-2.00))$. However, testosterone, androstenedione, and progesterone did not

Table 1 Clinical characteristics of $\mathrm{CAH}$ patients and controls.

\begin{tabular}{llll}
\hline & $\begin{array}{l}\text { Patients } \\
(n=16)\end{array}$ & $\begin{array}{l}\text { Controls } \\
(n=16)\end{array}$ & $\boldsymbol{P}$ \\
\hline Age (years) & $28.5(19-40)$ & $28.5(19-40)$ & $\mathrm{NS}$ \\
Menarche (years) & $12(10-17)$ & $13(12-16)$ & $\mathrm{NS}$ \\
BMI (kg/m $\left.{ }^{2}\right)$ & $24.2(18.6-46.0)$ & $23.1(19.8-25.5)$ & $\mathrm{NS}$ \\
SW/SV & $11 / 5$ & & \\
Menstrual cycles & & 16 & 0.002 \\
$\quad$ Regular & 6 & & \\
Oligomenorrhea & 4 & 3 & 0.22 \\
$\begin{array}{l}\text { Amenorrhea } \\
\text { Prior pregnancy }\end{array}$ & 6 & $0.83(0.72-1.14)$ & 0.06 \\
W/H ratio & $0.87(0.64-1.15)$ & 0.007 \\
Hirsutism & 7 & 0 & 0.007 \\
\hline
\end{tabular}

W/H, waist/hip; NS, not statistically significant. 
Table 2 Hormonal characteristics of CAH patients and controls.

\begin{tabular}{|c|c|c|c|}
\hline & $\begin{array}{l}\text { Patients } \\
(n=16)\end{array}$ & $\begin{array}{l}\text { Controls } \\
(n=16)\end{array}$ & $P$ \\
\hline $\begin{array}{l}\text { 17-OH progesterone } \\
(\mathrm{ng} / \mathrm{ml})\end{array}$ & $8.04(0.19-475.00)$ & $0.83(0.40-2.00)$ & 0.004 \\
\hline $\begin{array}{l}\text { Progesterone } \\
(\mathrm{ng} / \mathrm{ml})\end{array}$ & $1.12(0.05-27.02)$ & $0.49(0.18-1.08)$ & NS \\
\hline $\begin{array}{l}\text { Testosterone } \\
(\mathrm{ng} / \mathrm{ml})\end{array}$ & $0.12(0.06-4.24)$ & $0.21(0.12-0.44)$ & NS \\
\hline $\begin{array}{l}\text { Androstenedione } \\
(\mathrm{ng} / \mathrm{ml})\end{array}$ & $1.0(0.3-29.6)$ & $1.5(0.7-2.8)$ & NS \\
\hline SHBG (nmol/l) & $73.2(14-191.9)$ & $60.1(31.2-97.9)$ & NS \\
\hline Estradiol & $69(27-222)$ & $38(12-94)$ & 0.02 \\
\hline FSH (IU/I) & $4.9(0.1-9.6)$ & $5.8(4.5-19.9)$ & 0.03 \\
\hline LH (IU/I) & $4.95(0.1-10.1)$ & $5.0(3.8-15.2)$ & NS \\
\hline FSH/LH ratio & $1.0(0.5-9.6)$ & $1.2(0.7-2.6)$ & NS \\
\hline
\end{tabular}

NS, not statistically significant.

differ between patients and controls, but there was a wide range of values among $\mathrm{CAH}$ patients. At pelvic sonography, three patients had polycystic ovary morphology (18).

\section{LH pulsatility analysis}

No differences were observed between patients and controls, either for mean LH levels (4.95 IU/l (0.1-10.1) vs $5.0 \mathrm{IU} / \mathrm{l}(3.8-15.2)$ respectively, $P=\mathrm{NS})$ or for mean LH pulse amplitude (5.2 IU/l (0.1-11.0) vs $6.1 \mathrm{IU} / \mathrm{l}$ $(3.8-14.2), P=\mathrm{NS})$ or area $(106.1(0.1-352.1)$ vs 61.3 (13.8-254.0), $P=\mathrm{NS})$. However, LH pulse frequency tends to be lower in $\mathrm{CAH}$ patients than in control women $(2(0-5)$ vs $4(1-5), P=0.03)$ but did not reach the level of significance.

In $\mathrm{CAH}$ patients, LH pulsatility results were heterogeneous, with a broad range of values and profiles. Using factor analysis, we found that there were two underlying factors in the pulsatility data. The first factor was related to pulse area, pulse amplitude variability, and pulse area variability. The second factor was strongly correlated with pulse amplitude and mean LH. Frequency was correlated with both factors, positively with the first factor and negatively with the second factor. Cluster analysis of LH pulsatility data in the $\mathrm{CAH}$ patients resulted in a three-cluster partition (Fig. 1a). Individuals in the same cluster had similar results in terms of pulse frequency, pulse amplitude, pulse area, LH mean, pulse amplitude variability, and pulse area variability. The clusters were named cluster $1(n=7)$, cluster $2(n=7)$, and cluster $3(n=2)$, with clusters 2 and 3 being the two nearest clusters. On adding the controls, we noticed that 15 of the 16 controls were associated with cluster 1 and that clusters 2 and 3 were merged together (Fig. 1b). Consequently, we finally chose to partition the $\mathrm{CAH}$ patients into two groups: one with patients of cluster 1 (LH profile similar to controls, $n=7$ ) and one with patients of clusters 2 and 3 (different LH profile from controls with lower and wider LH pulse, $n=9$ ). In cluster 1 , median LH levels were 5.37 (3.67-8.47) IU/l, LH pulse amplitude was 6.68 (4.07-10.32) IU/l, and the LH pulse number was 4 (3-5); in cluster 2, median LH levels were $1.73(0.10-6.74)$ IU/l, LH pulse amplitude was 3.05 (1.41-11.03) IU/l, and the LH pulse number was $1(0-2)$. Two patients had undetectable LH levels during the study period.
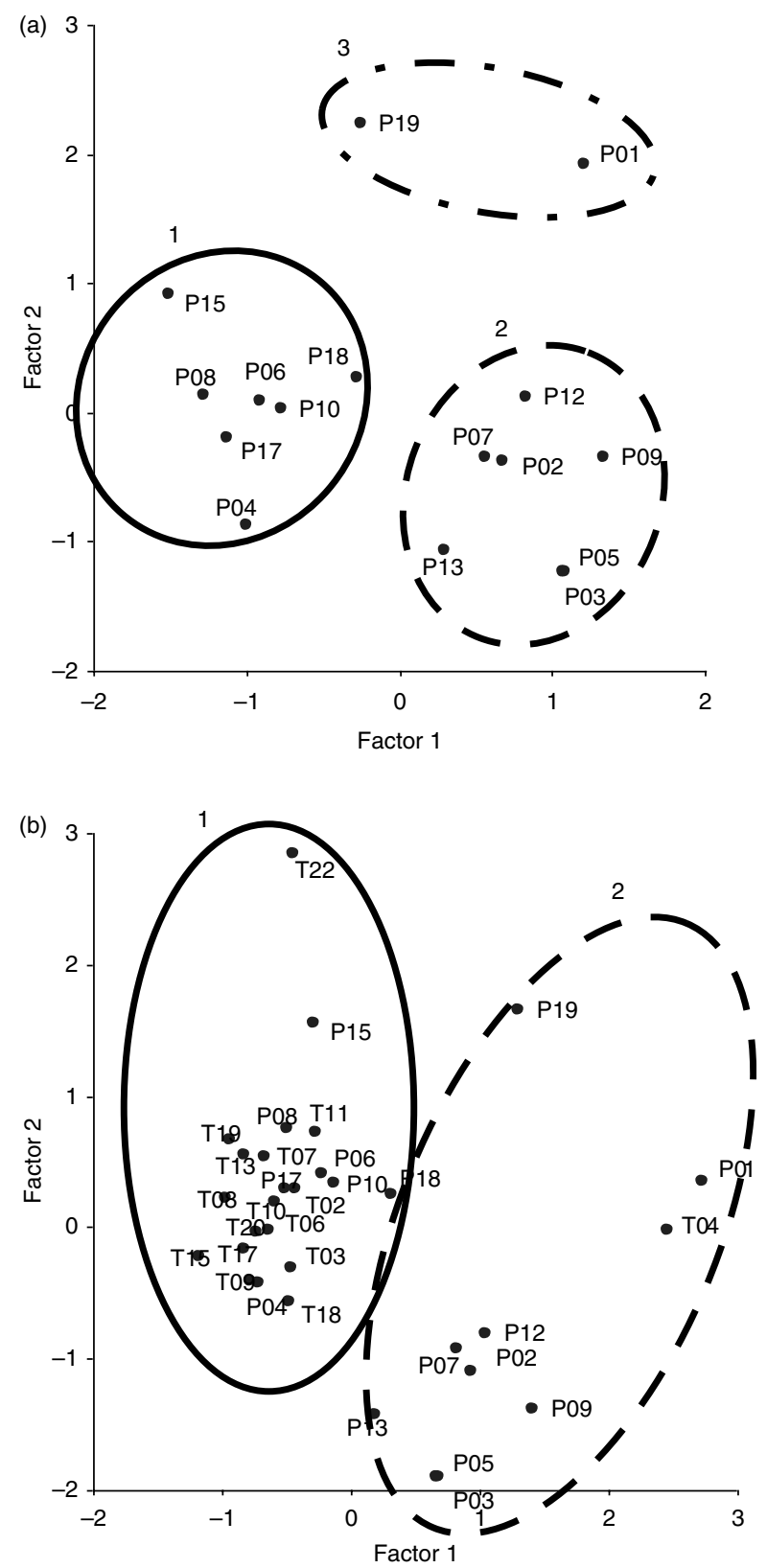

Figure 1 Projection of subjects by cluster group on the factor loadings plot. Factor analysis was performed to obtain the best graphical visualization view of LH data dispersion. (a) Shows the three clusters obtained in $\mathrm{CAH}$ patients only. (b) Shows the two clusters obtained with all subjects. Patients of cluster 3 are merged with cluster 2 . 
Table 3 Comparison of clinical characteristics between patients in clusters 1 and 2 .

\begin{tabular}{|c|c|c|c|}
\hline & \multicolumn{2}{|c|}{ CAH patients } & \multirow[b]{2}{*}{$P$} \\
\hline & Cluster $1(n=7)$ & Cluster $2(n=9)$ & \\
\hline Age (years) & $33.0(24.0-40.0)$ & $24.0(19.0-40.0)$ & NS \\
\hline Menarche (years) & $12(11-15)$ & $13(10-17)$ & NS \\
\hline BMI $\left(\mathrm{kg} / \mathrm{m}^{2}\right)$ & $24.2 \pm 5.2$ & $27.3 \pm 8.2$ & NS \\
\hline $\mathrm{W} / \mathrm{H}$ ratio & $0.87(0.83-0.95)$ & $0.85(0.64-1.15)$ & NS \\
\hline $\begin{array}{l}\text { Regular menstrual } \\
\text { cycles }\end{array}$ & 5 & 1 & 0.03 \\
\hline Genotype O/A/B & $0 / 4 / 3$ & $1 / 4 / 4$ & NS \\
\hline $\begin{array}{l}\text { Hydrocortisone } \\
\text { (mg/day) }\end{array}$ & $20(15-35)$ & $20(10-30)$ & NS \\
\hline
\end{tabular}

W/H, waist/hip; NS, not statistically significant.

When CAH patients were compared between clusters 1 and 2, no differences were observed regarding age, age at menarche, BMI, waist/hip ratio, genotype, or daily dose of hydrocortisone (Table 3). Patients in cluster 1 had more frequently regular menstrual cycles. Two patients in cluster 1 did not have regular menstrual cycles: one presented with short menstrual cycles of about 20 days; the other one presented with primary oligomenorrhea, and a long history of poor therapeutic compliance, but she had good hormonal control on the day of the study, suggesting at least short-term treatment compliance. One patient had polycystic ovary morphology at sonography, but regular menstrual cycle and normal androgen levels. In cluster 2 , most patients $(8 / 9)$ had oligomenorrhea or amenorrhea, but only one had polycystic ovary morphology. The remaining patient (P12) had regular menstrual cycles and good hormonal control. However, pelvic sonography revealed polycystic ovary morphology and hormonal monitoring of the cycles showed dysovulation.

There was a considerable difference between patients in clusters 1 and 2 regarding hormonal control of their disease, with higher 17-OHP, testosterone, progesterone, and androstenedione levels and lower FSH levels (Table 4) in cluster 2 patients than in cluster 1 patients. Adequate therapy control, arbitrarily defined by $17-\mathrm{OHP}<25 \mathrm{ng} / \mathrm{ml}$ and/or testosterone $<0.5 \mathrm{ng} / \mathrm{ml}$, was present in all patients in cluster 1 and only in two patients in cluster 2 . The plot of testosterone concentration as a function of progesterone by cluster shows that progesterone levels were sufficient to separate both clusters. Consequently, there is no evidence that testosterone provides supplementary information for prediction of cluster if the progesterone level is known.

\section{Discussion}

This study is the first to describe LH pulsatility patterns in women with classical $\mathrm{CAH}$, therefore highlighting the mechanism of anovulation in these women.
This would help us to define a precise hormonal objective in these women. We showed that these adult women may have LH pulsatility and secretion similar to control women and that hormonal control is a key factor in normal LH pulsatility. Moreover, we demonstrated that poor hormonal control is associated with reduced LH pulse frequency and amplitude, most probably due to progesterone oversecretion.

Disturbance of the menstrual cycle is common in women with classical $\mathrm{CAH}$ and has been attributed to anovulation that could be the consequence of prenatal exposure to androgens leading to PCOS (11). Indeed, the classical form of CAH is an excellent model to study the impact of prenatal androgen on the gonadotropic axis. In a previous study, where LH secretion was compared between women with classical and $\mathrm{NC} \mathrm{CAH}$ forms, only women with the classical form exposed early to androgens exhibited elevation of basal $\mathrm{LH}$ and $\mathrm{LH}$ responses to a GNRH agonist (12). Moreover, a study in girls with CAH during the first months of life showed that after adrenal steroid suppression, serum LH and serum FSH/serum LH ratios were similar to those of control boys, suggesting that fetal or perinatal androgenic steroids have an effect on the control of LH secretion that persists after androgen withdrawal (12). However, we demonstrated that classical $\mathrm{CAH}$ women with good hormonal control have LH pulsatility patterns similar to control women, suggesting the absence of neonatal programming of a disrupted gonadotropic axis, but rather adrenal steroid impact on the gonadotropic axis. It is of importance that none of our patients had early in utero exposure to dexamethasone. Moreover, none of our patients exhibited PCOS-like LH pulse patterns, with elevated LH pulse levels and amplitude.

The results of our study differ also from those previously published in NC CAH women (5). However, these latter results cannot be extrapolated to women with the classical form of $\mathrm{CAH}$, as $\mathrm{NC} \mathrm{CAH}$ patients are not exposed to adrenal progesterone oversecretion.

Table 4 Comparison of hormonal characteristics between patients in clusters 1 and 2 .

\begin{tabular}{|c|c|c|c|}
\hline & \multicolumn{2}{|c|}{ CAH patients } & \multirow[b]{2}{*}{$P$} \\
\hline & Cluster $1(n=7)$ & Cluster $2(n=9)$ & \\
\hline $\begin{array}{l}\text { 17-OH progesterone } \\
(\mathrm{ng} / \mathrm{ml})\end{array}$ & $1.0(0.2-2.5)$ & $60.0(2.8-475.0)$ & 0.005 \\
\hline $\begin{array}{l}\text { Progesterone } \\
(\mathrm{ng} / \mathrm{ml})\end{array}$ & $0.05(0.05-0.44)$ & $5.78(0.55-27.02)$ & 0.004 \\
\hline Testosterone (ng/ml) & $0.06(0.06-0.26)$ & $0.39(0.06-4.24)$ & 0.01 \\
\hline $\begin{array}{l}\text { Androstenedione } \\
(\mathrm{ng} / \mathrm{ml})\end{array}$ & $0.6(0.4-1.5)$ & $3.1(0.3-29.6)$ & 0.05 \\
\hline SHBG (nmol/l) & $90.9(49.1-191.9)$ & $61.4(14-98)$ & NS \\
\hline Estradiol (pg/ml) & $64(34-84)$ & $98(27-221)$ & NS \\
\hline FSH (IU/I) & $6.1(4.7-9.6)$ & $3.5(0.1-8.3)$ & 0.02 \\
\hline LH (IU/I) & $6.2(4.8-9.5)$ & $2.3(0.1-10.1)$ & 0.01 \\
\hline FSH/LH ratio & $1.0(0.5-2.0)$ & $1.2(0.8-9.6)$ & NS \\
\hline
\end{tabular}

NS, not statistically significant. 
Hormonal control was the best predictor of LH pulsatility in our study. The role of ovarian steroid hormones on the regulation of gonadotropin secretion has been studied for many years. The major effect of progesterone is a decrease in LH pulse frequency. Administration of progesterone to normal women during the follicular phase decreases LH pulse frequency from one pulse every hour to one pulse every $4 \mathrm{~h}$ (19). It is well known that progesterone acts at the hypothalamic level and inhibits GNRH pulse frequency (20). More recently, it has been shown that progesterone also acts directly at the pituitary level $(20,21,22)$. Little is known about the effects of androgens on gonadotropin secretion in women. Short-term studies indicate that testosterone infusion inhibits LH release in a dosedependent manner. Moderately induced elevation of plasma testosterone levels in women has a suppressive effect only on LH pulse frequency, whereas higher testosterone levels reduce both the frequency and the amplitude of LH pulses $(23,24,25)$. In our study, LH pulsatility profiles, with reduced pulse frequency and amplitude, suggest progesterone action on the gonadotropic axis rather than androgen action. This was corroborated by the plot analysis of progesterone concentrations vs testosterone concentrations. Unfortunately, multivariate analysis could not be performed due to the low number of patients.

Infertility is a common problem in classical $\mathrm{CAH}$ women. The first large study has shown that among 25 women with the SV form and adequate vaginal opening, the fertility rate was $60 \%$, meanwhile among the 15 women with the SW form with adequate vaginal opening, the fertility rate was only $7 \%$ (26). However, more recent data suggest that fertility rates have significantly improved, largely owing to earlier treatment of $\mathrm{CAH}$, improvement of compliance with therapy, and surgical advances in genital reconstruction leading to an increased percentage of patients with sexual activity $(27,28)$. Moreover, a recent study has presented for the first time the pregnancy rate as the proportion of women who were actively trying to conceive and reported a near normal conception rate for women with classical CAH (29). To achieve this, they focused on combined suppression of serum progesterone concentrations in the follicular phase of the menstrual cycle and plasma renin activity. Our study strengthened the impact of progesterone overproduction in menstrual cycle disturbance in $\mathrm{CAH}$ patients and the importance of carefully monitoring and suppression of progesterone production to obtain optimal control of menstrual cycles.

In conclusion, CAH women do not necessarily present disruption of the gonadotropic axis and anovulation due to early exposure to adrenal steroids. Optimized glucocorticoid and mineralocorticoid regimes during fertility monitoring should thus be an important concern in CAH women, and in particular, suppression of serum progesterone concentrations during the follicular phase of the menstrual cycle should be a major objective in these patients.

\section{Declaration of interest}

The authors declare that there is no conflict of interest that could be perceived as prejudicing the impartiality of the research reported.

\section{Funding}

This work was supported by a grant from Association Surrénales.

\section{Author contribution statement}

A Bachelot designed the study and analyzed the data and wrote parts of the manuscript, Z Chakhtoura and J Dulon designed the study and reviewed the manuscript. G Plu-Bureau and M Coudert analyzed the data and performed LH pulsatility analysis. C Coussieu performed hormonal assessment and Y Badachi ovarian ultrasonography, and $\mathrm{P}$ Touraine, the main investigator of the CAHLH study, reviewed the manuscript.

\section{Acknowledgements}

CAHLH study group: Jean-Paul Akakpo, Christine Béllané-Chantelot, Thierry Brue, Carine Courtillot, Laetitia Jacquesson, Frédérique Kuttenn, Yves Morel, Yves Reznik, Hélène Scherrer, Véronique Tardy, and Jacques Young.

\section{References}

1 White PC \& Speiser PW. Congenital adrenal hyperplasia due to 21-hydroxylase deficiency. Endocrine Reviews 200021 245-291. (doi:10.1210/er.21.3.245)

2 Ogilvie CM, Crouch NS, Rumsby G, Creighton SM, Liao LM \& Conway GS. Congenital adrenal hyperplasia in adults: a review of medical, surgical and psychological issues. Clinical Endocrinology 200664 2-11. (doi:10.1111/j.1365-2265.2005.02410.x)

3 Helleday J, Siwers B, Ritzen EM \& Carlstrom K. Subnormal androgen and elevated progesterone levels in women treated for congenital virilizing 21-hydroxylase deficiency. Journal of Clinical Endocrinology and Metabolism 1993 76 933-936. (doi:10.1210/jc. 76.4.933)

4 Holmes-Walker DJ, Conway GS, Honour JW, Rumsby G \& Jacobs HS. Menstrual disturbance and hypersecretion of progesterone in women with congenital adrenal hyperplasia due to 21-hydroxylase deficiency. Clinical Endocrinology $1995 \mathbf{4 3}$ 291-296. (doi:10.1111/j.1365-2265.1995.tb02034.x)

5 Levin JH, Carmina E \& Lobo RA. Is the inappropriate gonadotropin secretion of patients with polycystic ovary syndrome similar to that of patients with adult-onset congenital adrenal hyperplasia? Fertility and Sterility $19915 \mathbf{5 6} 635-640$.

6 Rebar R, Judd HL, Yen SS, Rakoff J, Vandenberg G \& Naftolin F. Characterization of the inappropriate gonadotropin secretion in polycystic ovary syndrome. Journal of Clinical Investigation 197657 1320-1329. (doi:10.1172/JCI108400)

7 Taylor AE, McCourt B, Martin KA, Anderson EJ, Adams JM, Schoenfeld D \& Hall JE. Determinants of abnormal gonadotropin secretion in clinically defined women with polycystic ovary syndrome. Journal of Clinical Endocrinology and Metabolism 1997 82 2248-2256. (doi:10.1210/jc.82.7.2248)

8 Pastor CL, Griffin-Korf ML, Aloi JA, Evans WS \& Marshall JC. Polycystic ovary syndrome: evidence for reduced sensitivity of the gonadotropin-releasing hormone pulse generator to inhibition by estradiol and progesterone. Journal of Clinical Endocrinology and Metabolism 1998 83 582-590. (doi:10.1210/jc.83.2.582) 
9 Chhabra S, McCartney CR, Yoo RY, Eagleson CA, Chang RJ \& Marshall JC. Progesterone inhibition of the hypothalamic gonadotropin-releasing hormone pulse generator: evidence for varied effects in hyperandrogenemic adolescent girls. Journal of Clinical Endocrinology and Metabolism 200590 2810-2815. (doi:10.1210/jc.2004-2359)

10 Eagleson CA, Gingrich MB, Pastor CL, Arora TK, Burt CM, Evans WS \& Marshall JC. Polycystic ovarian syndrome: evidence that flutamide restores sensitivity of the gonadotropin-releasing hormone pulse generator to inhibition by estradiol and progesterone. Journal of Clinical Endocrinology and Metabolism 200085 4047-4052. (doi:10.1210/jc.85.11.4047)

11 Barnes RB, Rosenfield RL, Ehrmann DA, Cara JF, Cuttler L, Levitsky LL \& Rosenthal IM. Ovarian hyperandrogynism as a result of congenital adrenal virilizing disorders: evidence for perinatal masculinization of neuroendocrine function in women. Journal of Clinical Endocrinology and Metabolism 199479 1328-1333. (doi:10.1210/jc.79.5.1328)

12 Belgorosky A, Chahin S \& Rivarola MA. Elevation of serum luteinizing hormone levels during hydrocortisone treatment in infant girls with 21-hydroxylase deficiency. Acta Paediatrica 1996 85 1172-1175. (doi:10.1111/j.1651-2227.1996.tb18223.x)

13 Bachelot A, Plu-Bureau G, Thibaud E, Laborde K, Pinto G, Samara D, Nihoul-Fékété C, Kuttenn F, Polak M \& Touraine P. Long-term outcome of patients with congenital adrenal hyperplasia due to 21-hydroxylase deficiency. Hormone Research 2007 67 268-276. (doi:10.1159/000098017)

14 Hatch R, Rosenfield RL, Kim MH \& Tredway D. Hirsutism: implications, etiology, and management. American Journal of Obstetrics and Gynecology 1981140 815-830.

15 Veldhuis JD \& Johnson ML. Cluster analysis: a simple, versatile, and robust algorithm for endocrine pulse detection. American Journal of Physiology 1986250 E486-E493.

16 Evans WS, Sollenberger MJ, Booth RA Jr, Rogol AD, Urban RJ, Carlsen EC, Johnson ML \& Veldhuis JD. Contemporary aspects of discrete peak-detection algorithms. II. The paradigm of the luteinizing hormone pulse signal in women. Endocrine Reviews 199213 81-104. (doi:10.1210/edrv-13-1-81)

17 Ward J. Hierarchical grouping to optimize an objective function. Journal of the American Statistical Association 196358 236-244. (doi:10.1080/01621459.1963.10500845)

18 RotterdamESHRE/ASRM-Sponsored PCOS consensus workshop group. Revised 2003 consensus on diagnostic criteria and longterm health risks related to polycystic ovary syndrome (PCOS). Human Reproduction 200419 41-47. (doi:10.1093/humrep/ deh098)

19 Couzinet B, Young J, Brailly S, Chanson P, Thomas JL \& Schaison G. The antigonadotropic activity of progestins (19-nortestosterone and 19-norprogesterone derivatives) is not mediated through the androgen receptor. Journal of Clinical Endocrinology and Metabolism 199681 4218-4223. (doi:10.1210/jc.81.12.4218)

20 Soules MR, Steiner RA, Clifton DK, Cohen NL, Aksel S \& Bremner WJ. Progesterone modulation of pulsatile luteinizing hormone secretion in normal women. Journal of Clinical Endocrinology and Metabolism 198458 378-383. (doi:10.1210/ jcem-58-2-378)

21 Couzinet B, Young J, Kujas M, Meduri G, Brailly S, Thomas JL, Chanson $\mathrm{P} \&$ Schaison G. The antigonadotropic activity of a 19-nor-progesterone derivative is exerted both at the hypothalamic and pituitary levels in women. Journal of Clinical Endocrinology and Metabolism $1999 \mathbf{8 4}$ 4191-4196. (doi:10. 1210/jc.84.11.4191)

22 Bry-Gauillard H, Meduri G, Abirached F, Constancis E, Brailly S, Chanson P \& Young J. Primary amenorrhea revealing an occult progesterone-secreting ovarian tumor. Fertility and Sterility 200890 1198.e1-1198.e5. (doi:10.1016/j.fertnstert.2007.11. 064)

23 Dewis P, Newman M, Ratcliffe WA \& Anderson DC. Does testosterone affect the normal menstrual cycle? Clinical Endocrinology 198624 515-521. (doi:10.1111/j.1365-2265.1986. tb03280.x)

24 Dunaif A. Do androgens directly regulate gonadotropin secretion in the polycystic ovary syndrome? Journal of Clinical Endocrinology and Metabolism 198663 215-221. (doi:10.1210/ jcem-63-1-215)

25 Serafini P, Silva PD, Paulson RJ, Elkind-Hirsch K, Hernandez M \& Lobo RA. Acute modulation of the hypothalamic-pituitary axis by intravenous testosterone in normal women. American Journal of Obstetrics and Gynecology 1986155 1288-1292.

26 Mulaikal RM, Migeon CJ \& Rock JA. Fertility rates in female patients with congenital adrenal hyperplasia due to 21-hydroxylase deficiency. New England Journal of Medicine 1987316 178-182. (doi:10.1056/NEJM198701223160402)

27 Jaaskelainen J, Hippelainen M, Kiekara O \& Voutilainen R. Child rate, pregnancy outcome and ovarian function in females with classical 21-hydroxylase deficiency. Acta Obstetricia et Gynecologica Scandinavica 200079 687-692. (doi:10.1034/j. 1600-0412.2000.079008687.x)

28 Hoepffner W, Schulze E, Bennek J, Keller E \& Willgerodt H. Pregnancies in patients with congenital adrenal hyperplasia with complete or almost complete impairment of 21-hydroxylase activity. Fertility and Sterility 200481 1314-1321. (doi:10.1016/ j.fertnstert.2003.10.024)

29 Casteràs A, De Silva P, Rumsby G \& Conway GS. Reassessing fecundity in women with classical congenital adrenal hyperplasia (CAH): normal pregnancy rate but reduced fertility rate. Clinical Endocrinology 2009 70 833-837. (doi:10.1111/j.1365-2265. 2009.03563.x)

Received 24 May 2012

Revised version received 13 July 2012

Accepted 14 August 2012 